\title{
Garlic lowers blood pressure in hypertensive subjects, improves arterial stiffness and gut microbiota: A review and meta-analysis
}

\author{
KARIN RIED ${ }^{1-3}$ \\ ${ }^{1}$ National Institute of Integrative Medicine (NIIM), Hawthorn, Melbourne, Victoria 3122; ${ }^{2}$ Department of General Practice, \\ The University of Adelaide, South Australia 5000; ${ }^{3}$ Torrens University, Melbourne, Victoria 3000, Australia
}

Received July 5, 2019; Accepted August 9, 2019

DOI: $10.3892 /$ etm.2019.8374

\begin{abstract}
Garlic supplements have shown effectiveness in reducing blood pressure in hypertensive patients, similarly to first-line standard anti-hypertensive medications. Kyolic garlic has also shown promise in improving cardiovascular health by reducing arterial stiffness, elevated cholesterol levels and blood 'stickiness'. In addition, the prebiotic properties in garlic increase gut microbial richness and diversity. This article systematically reviews previously published trials investigating the effects of garlic on blood pressure, and provides an updated meta-analysis of hypertensive participants. In addition, we summarise the findings of recent clinical trials investigating the effects of Kyolic aged garlic extract on arterial stiffness, and gut microbiota in hypertensive subjects. We searched online electronic databases, including PubMed and Google Scholar for randomised controlled trials (RCTs) published between 1955 and December, 2018 examining the effects of garlic on high blood pressure. The meta-analysis of 12 trials and 553 hypertensive participants confirmed that garlic supplements lower systolic blood pressure (SBP) by an average of $8.3 \pm 1.9 \mathrm{mmHg}$ and diastolic blood pressure (DBP, $\mathrm{n}=8$ trials, $\mathrm{n}=374$ subjects) by $5.5 \pm 1.9 \mathrm{mmHg}$, similarly to standard anti-hypertensive medications. This reduction in blood pressure was associated with a $16-40 \%$ reduction in the risk of suffering from cardiovascular events. Additionally, this review summarises new evidence for the vitamin B12 status playing an important role in the responsiveness of blood pressure to garlic. Furthermore, Kyolic aged garlic extract significantly lowered central blood pressure, pulse pressure, pulse wave
\end{abstract}

Correspondence to: Professor Karin Ried, National Institute of Integrative Medicine (NIIM), 21 Burwood Road, Hawthorn, Victoria 3122, Australia

E-mail: karinried@niim.com.au

Abbreviations: DBP, diastolic blood pressure; SBP, systolic blood pressure; $\mathrm{H}_{2} \mathrm{~S}$, hydrogen sulphide; $\mathrm{PWV}$, pulse wave velocity

Key words: aged garlic extract, blood pressure, hypertension, meta-analysis, pulse wave velocity, arterial stiffness, gut microbiome velocity and arterial stiffness, and improved the gut microbiota, evidenced by higher microbial richness and diversity, with a marked increase in the numbers of Lactobacillus and Clostridia species found following 3 months of supplementation. Thus, Kyolic aged garlic extract is considered to be highly tolerable with a high safety profile either as a stand-alone or adjunctive anti-hypertensive treatment, with multiple benefits for cardiovascular health.

\section{Introduction}

Previous meta-analyses and recent clinical trials have demonstrated that garlic supplements, including Kyolic aged garlic extract, are effective in reducing blood pressure in patients with uncontrolled hypertension, similar to first-line standard anti-hypertensive medications (1-8). Uncontrolled hypertension, defined as systolic blood pressure (SBP) $\geq 140 \mathrm{mmHg}$ and/or a diastolic blood pressure (DBP) $\geq 90 \mathrm{mmHg}$, including treated and untreated hypertensive patients, is prevalent in about a quarter $(25 \%)$ of the adult population in Western countries (9). Up to $62 \%$ of patients on standard blood pressure medication experience adverse effects, such as fatigue, cold hands/feet, dry mouth, dizziness, headaches, muscular cramp/myalgia (10), thus highlighting the need for a more tolerable alternative therapeutic option.

A recent meta-analysis on the effects of garlic supplements on blood pressure, including 20 trials and $>900$ participants, revealed a significant effect of garlic on blood pressure, with an average decrease in SBP of $8.6 \mathrm{~mm}$ and $6.1 \mathrm{~mm}$ in DBP in hypertensive subjects ( $n=14$ trial arms, $n=468$ participants) (4).

To date, our group has conducted a number of clinical trials investigating the effects of Kyolic on blood pressure (5-8). Our first clinical trial including a pre-hypertensive group of adults (SBP $\geq 130 \mathrm{mmHg}$ ) revealed that Kyolic garlic significantly reduced blood pressure in the hypertensive subgroup (SBP $\geq 140 \mathrm{mmHg}$ ), but not in the normotensive subgroup (SBP $<140 \mathrm{mmHg}$ ) (5). This suggests that Kyolic aged garlic extract normalises blood pressure, in contrast to standard blood pressure medications, including angiotensin-converting enzyme inhibitors (ACEIs), angiotensin receptor blockers (ARBs), beta blockers (BBs), calcium channel blockers (CCBs), diuretics (Ds), which may sometimes lead to hypotension.

Our second dose-response trial revealed that a dose of 2 capsules/day of Kyolic aged garlic extract was sufficient to 
achieve an average blood pressure-lowering effect of $10 \mathrm{mmHg}$ systolic and $5 \mathrm{mmHg}$ diastolic, within 2-3 months (6). By contrast, 1 capsule per day was insufficient, whereas 4 capsules/day were not superior to 2 capsules/day. Two capsules of the High Potency Formula of Kyolic (Wagner/Nutralife available in Australia/New Zealand) contains $480 \mathrm{mg}$ of concentrated aged garlic extract powder and $1.2 \mathrm{mg} S$-allyl cysteine (SAC), and are equivalent to 2 capsules of the Reserve Formula of Kyolic (Wakunaga of America available in the USA), containing $1.2 \mathrm{~g}$ of aged garlic extract powder and $1.2 \mathrm{mg}$ of SAC.

In our third 'AGE at Heart' trial we found Kyolic to be effective in reducing peripheral blood pressure, as well as central blood pressure, central pulse pressure, pulse wave velocity and arterial stiffness (7). Central hemodynamic measures, such as central blood pressure, pulse wave velocity, pulse pressure and arterial stiffness, are regarded as more important predictors than peripheral blood pressure for cardiovascular disease risk $(11,12)$. Arterial stiffness, an indicator of the flexibility of the arteries, increases with age through the loss of intact elastin and collagen fibres in the arterial wall $(13,14)$, which also contributes to increased blood pressure (15). Kyolic aged garlic extract has been shown to be effective in reducing arterial stiffness, which in turn is related to better heart health and aerobic fitness, while the risk of cardiovascular disease is reduced $(7,8,12)$.

While in the 'AGE at Heart' trial (7), the average blood pressure reduction observed in the garlic group $(n=50)$ compared to the placebo $(n=38)$ was statistically significant and comparable to that of previous studies $(5,6)$, in a subgroup of participants, blood pressure was not appreciably altered (SBP $\leq 5 \mathrm{mmHg}, \mathrm{DBP} \leq 3 \mathrm{mmHg}$ ) over the 3 months course of the study ( $n=21$ non-responders). We hypothesised that this non-response of blood pressure to garlic may be related to a deficiency in co-factors, including the $\mathrm{B}$ vitamins, and in particular folate, vitamin B2, vitamin B6 and vitamin B12, as these are essential co-factors in the mechanisms of action of garlic as regards the reduction of blood pressure (16).

Briefly, the mechanisms of action through which garlic influences blood pressure involve two main signalling pathways via nitric oxide (NO) and hydrogen sulphide $\left(\mathrm{H}_{2} \mathrm{~S}\right)$ production (16). Garlic, a sulphur donor, provides an important component for the trans-sulphuration pathway, which is linked to the methylation pathway, with both requiring several co-factors, such as vitamin B12, folate, vitamin B2 and vitamin B6. In addition, known genetic variants for the cystathionine- $\beta$-synthase (CBS) and cystathionine- $\gamma$-lyase (CSE) enzymes influence the efficiency of $\mathrm{H}_{2} \mathrm{~S}$ production, and thus are considered to play an important role in the susceptibility to developing hypertension, in conjunction with deficiencies in B vitamins. We have previously identified a potentially large proportion $(80 \%)$ of healthy adults in Australia with sub-optimal vitamin B12 levels $(<500 \mathrm{pg} / \mathrm{l})(17)$. Therefore, deficiencies in co-factors, such as vitamin B12, may explain the individual responsiveness of blood pressure to garlic observed in our clinical trials.

Furthermore, as high blood pressure has been linked to the dysbiosis of gut microbiota, both in animal and human studies, with a significant lower microbial richness and diversity in hypertensive subjects compared to normotensive subjects (18), we investigated the effects of Kyolic garlic on the microbiome in our most recent clinical study, the GarGIC trial (8). In general, a higher relative abundance/bacterial mass/microbial richness and a diversity of microbial species is associated with better health (18-20).

With its prebiotic properties, and the source of intracellular $\mathrm{H}_{2} \mathrm{~S}(16,21)$, garlic has the potential to modulate the gut microbiota (22), and to restore the microbiota biofilm and mucus production (23). The timeframe for changes to be observed in the composition of the gut microbiota with dietary supplementation is relatively short, as shown in a 4-week study of patients with irritable bowel syndrome taking probiotics daily (24). In addition, the consumption of probiotics has been shown to significantly reduce blood pressure, in particular in trials of $>8$ weeks duration (meta-analysis of 9 RCTs involving 534 patients) (25).

In this study, we revise the meta-analyses on garlic and blood pressure in hypertensive subjects, including additional recent clinical trials. In addition, we review the role of B vitamins in the responsiveness of blood pressure to garlic, and summarise the effects of Kyolic aged garlic extract on arterial stiffness and gut microbiota.

\section{Data and methods}

For the meta-analysis of the effects of garlic on blood pressure in hypertensive subjects, we included randomised double-blind placebo-controlled trials on garlic for blood pressure with a minimum of 2 months duration, identified in previous meta-analyses: Specifically, Silagy and Neil, 1994 (26), Reinhart et al, 2008 (2), Ried et al, 2008 (1), Rohner et al, 2014 (3) and Ried, 2016 (4). We extended the search in Medline for trials published between 1955 and December, 2018 with no language restrictions, using the search terms 'garlic' AND 'blood pressure' OR 'hypertension'.

We included studies with adults with uncontrolled hypertension [mean \pm standard deviation (SD): SBP, $\geq 140 \pm 2 \mathrm{mmHg}$ and/or DBP, $\geq 90 \pm 2 \mathrm{mmHg}$ ], using garlic-only supplements, and reporting the mean SBP and/or DBP with SD or standard error (SE) at baseline and at end of the intervention. We included hypertensive subjects on an established plan of blood pressure medication, or subjects who were not taking any blood pressure medication at time of the trial. We excluded trials and trial arms with normotensive subjects, trials or trial arms using garlic-combination products, and trials with a very high attrition rate (loss to follow-up, $>30 \%$ ).

For the meta-analysis, we entered the mean SBP and DBP into the Review Manager 5.3 program (27) using the inverse variance method and a random effects model. When blood pressure measurements were reported in $>1$ position, the order of preference was as follows: i) Sitting; ii) standing; and iii) in the supine position. When both clinical and ambulatory blood pressure measurements were available, the order of preference was as follows: i) clinical; and ii) ambulatory. If results were reported for several periods of follow-up, we selected the longest follow-up from each study for comparison with the baseline. The outcomes were calculated as mean differences in SBP and DBP between the garlic and control groups at the final follow-up adjusted for baseline. We assessed heterogeneity by the $\mathrm{I}^{2}$ statistic, and overall significance with a P-value using the Review Manager program, as outlined in the Cochrane Handbook (27). 


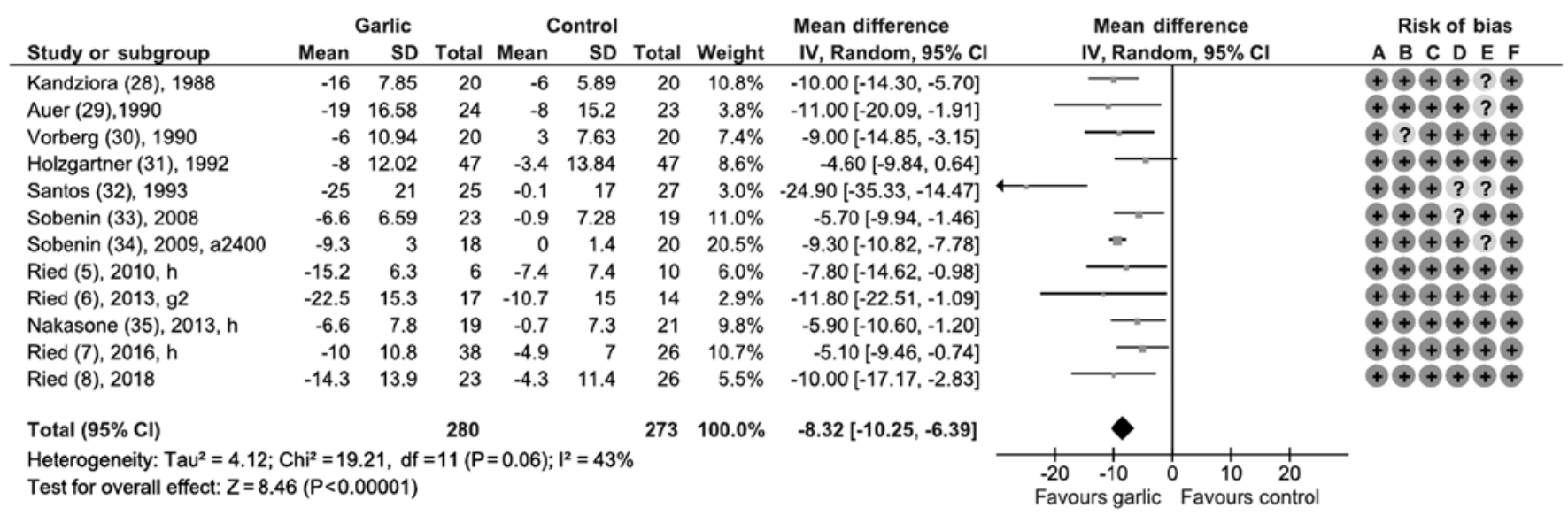

Risk of bias legend

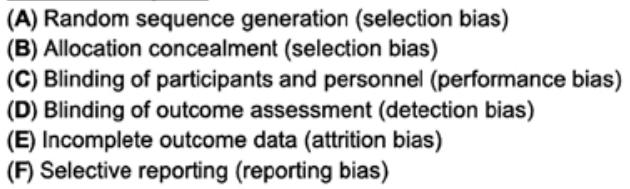

Figure 1. Meta-analysis of the effects of garlic on systolic blood pressure (SBP) in hypertensive adults. a2400, Allicor-2400mg group; g2, Kyolic garlic-2-capsule group; h, hypertensive subgroup; IV, inverse variance method; SD, standard deviation; $\mathrm{I}^{2}$ statistic of Heterogeneity; Weight; influence of study on meta-analysis depending on sample size and $95 \%$ CI.

The risk of bias for each trial included the assessment of random sequence generation (selection bias), allocation concealment (selection bias), incomplete outcome data (attrition bias), selective reporting (reporting bias), blinding of participants and personnel (performance bias), and the blinding of outcome assessment (detection bias) (27).

\section{Results}

A total of 12 trials involving 553 participants with hypertension were identified as meeting the inclusion criteria $(5-8,28-34)$, including 2 new trials $(7,8)$ that were not part of the most recently published meta-analyses (4). For trials with multiple intervention arms $(6,34)$, only the main arm was included in this updated meta-analysis, in order to avoid the double-counting of placebo groups. For trials with hypertensive and normotensive subgroups $(5,7,35)$, only the hypertensive subgroup was included in this updated meta-analysis (Table I).

Not all participants of the trials included in the meta-analysis on systolic hypertension also suffered from diastolic hypertension. Eight out of the 12 trials involving 374 subjects met the inclusion criteria for the meta-analysis of diastolic hypertension $(7,8,28-30,32,34,35)$.

A further two trials published between 2013 and 2018, examining the effects of a garlic product on blood pressure, were excluded from the meta-analysis, as one trial testing patients with severe coronary artery disease did not include hypertensive subjects (36), and the other trial was not of sufficient quality (37). The latter trial of 80 participants and 4 groups investigated a combination of garlic and coriander seed powder (details of active ingredients or production were not provided), did not report on compliance or loss-to-follow-up, and provided no placebo supplement to the control group (37).

The meta-analysis of 12 trials involving adults with hypertension confirmed that the garlic supplements significantly lowered SBP by $8.32 \pm 1.93 \mathrm{mmHg}(\mathrm{n}=12$ trials, $\mathrm{n}=553$ participants, $\mathrm{P}<0.00001)$, and DBP by $5.48 \pm 1.92 \mathrm{mmHg}(\mathrm{n}=8$ trials, $\mathrm{n}=374$ participants, $\mathrm{P}<0.00001$ ) (Figs. 1 and 2).

The included trials were of high quality with a minimal risk of bias (Figs. 1 and 2). An unclear risk of attrition bias was encountered in 2 trials $(28,29)$, which did not report on the loss to follow-up, one trial (32) reported $20 \%$ attrition in the garlic group and $11 \%$ in the placebo group, and another trial (33) reported $27 \%$ attrition in the garlic group, and none in the placebo group. No details on blood pressure measurements were reported in 2 trials $(32,33)$, leading to an unclear risk of detection bias, and no details on allocation concealment were reported in another trial (30). Resulting in an unclear risk of selection bias.

Eight out of the 12 trials used garlic powder, either Kwai manufactured in Germany $(n=5)(28-32)$, Allicor from Russia $(n=2)(33,34)$, or a garlic powder manufactured in Japan $(n=1)(35)$, while 4 trials investigated Kyolic aged garlic extract (5-8). Kyolic aged garlic extract powder is manufactured from organically grown garlic bulbs, which has undergone a 20 -month aging process in $70 \%$ ethanol at room temperature. During the aging process, volatile sulphur components found in raw garlic, such as allicin, are chemically converted into stable and standardisable components, including the main vasoactive component, SAC (38-40).

In two of our clinical trials, Ried et al, 2010 (5) and Ried et al, 2013 (6), we used the 'Kyolic High Potency Formula' available in Australia and New Zealand $(240 \mathrm{mg}$ of concentrated aged garlic extract containing $600 \mu \mathrm{g} \mathrm{SAC}$ per capsule). In our 2 previous trials [Ried et al, 2016 (7) and Ried et al, 2018 (8)], we used the 'Kyolic Reserve Formula' (600 mg of aged garlic extract powder containing $600 \mu \mathrm{g}$ SAC per capsule). Both Kyolic formulas are comparable by dosage of the active ingredient SAC (Table I). The majority of trials used between 600-900 mg of garlic powder per day 


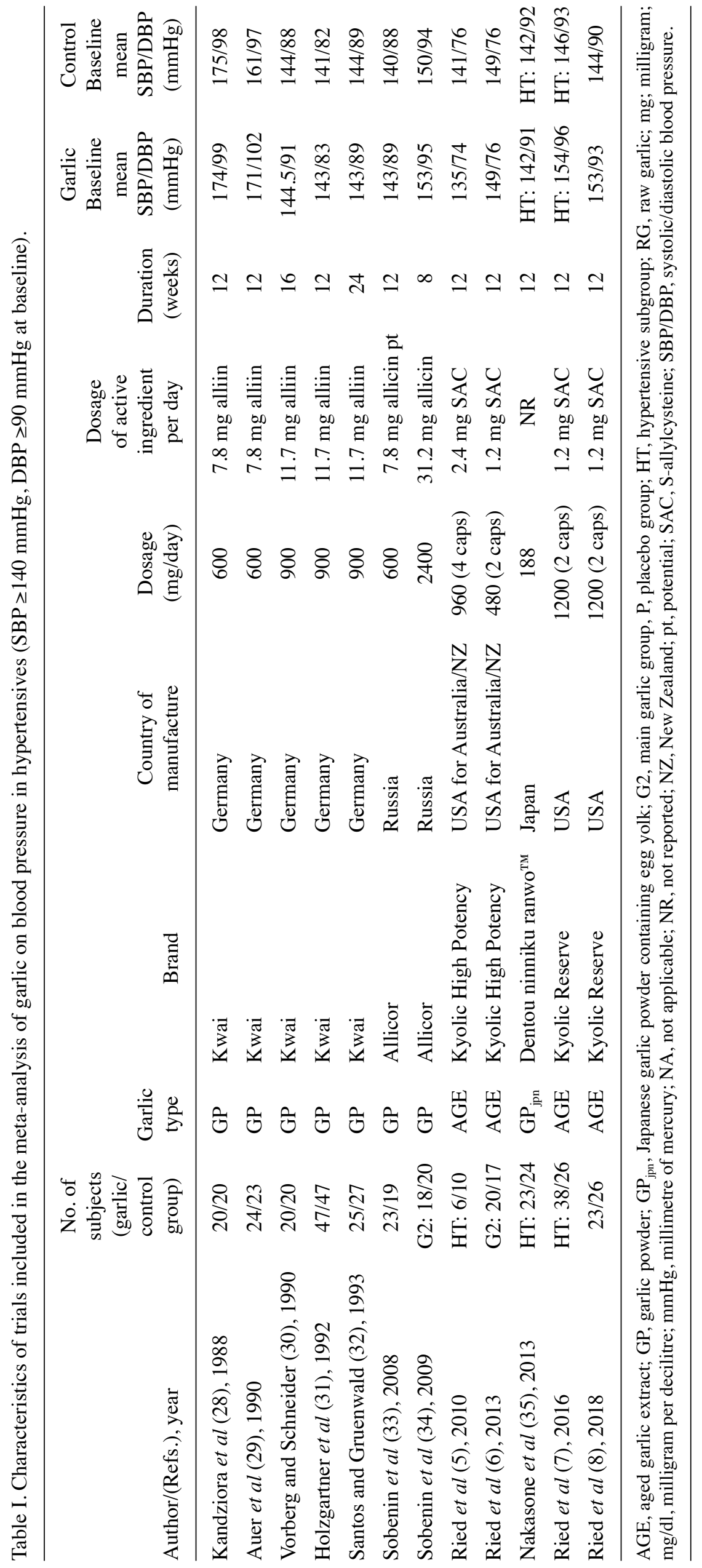




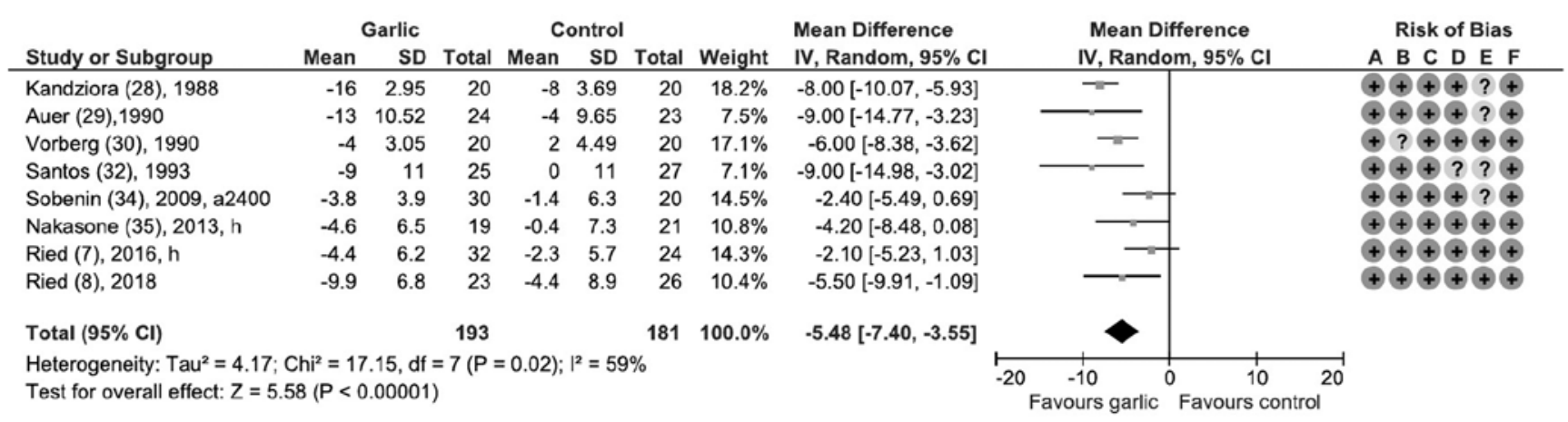

Risk of bias legend

(A) Random sequence generation (selection bias)

(B) Allocation concealment (selection bias)

(C) Blinding of participants and personnel (performance bias)

(D) Blinding of outcome assessment (detection bias)

(E) Incomplete outcome data (attrition bias)

(F) Selective reporting (reporting bias)

Figure 2. Meta-analysis of the effects of garlic on diastolic blood pressure (DBP) in hypertensive adults. a2400, Allicor-2400mg group; h, hypertensive subgroup; IV, inverse variance method; SD, standard deviation.

or 1,200 mg of Kyolic aged garlic extract for a median trial period of 12 weeks (Table I).

\section{Discussion}

Our meta-analyses on the effects of garlic on hypertension, including 12 trials and 553 adults with high blood pressure, suggested that garlic supplements significantly lower SBP by an average of $8.3 \pm 1.9 \mathrm{mmHg}$ and DBP $(\mathrm{n}=374)$ by $5.5 \pm 1.9 \mathrm{mmHg}$.

The average reduction in SBP of $8-10 \mathrm{mmHg}$ induced by garlic supplements, alone or in combination with other blood pressure medications, is comparable to that of conventional standard blood pressure drug therapeutics, estimated to reduce the risk of cardiovascular events, such as heart attack, coronary artery disease, or stroke by $16-40 \%(41,42)$.

In our clinical trials, in a proportion of participants, blood pressure was not appreciably altered $(>5 \mathrm{mmHg}$ SBP and $>3 \mathrm{mmHg}$ DBP; 30 or $17 \%$, respectively), possibly owing to a suboptimal B vitamin status $(7,8)$. Some B vitamins are important co-factors in the mechanisms of action through which sulphur components in garlic are transformed into $\mathrm{H}_{2} \mathrm{~S}$, serving as signalling molecules for smooth muscle cell relaxation and vasodilation, leading to a reduction in blood pressure $(16,43)$.

In addition to the beneficial effects of garlic supplements on blood pressure, we, as well as others have found that Kyolic aged garlic extract is effective in rejuvenating the arteries, as evidenced by a reduction in pulse wave velocity $(7,8,12)$. While arterial stiffness increases naturally with age by an average of $1.43 \mathrm{~m} / \mathrm{sec}$ pulse wave velocity in 10 years $(13,14)$, our findings suggested that Kyolic aged garlic extract has the potential to reverse the ageing of the arteries and therefore, arterial stiffness by approximately 5 years, as evidenced by a mean reduction in pulse wave velocity by $0.7 \mathrm{~m} / \mathrm{sec}$ within 3 months (8).

Furthermore, previous research suggests that garlic is effective in normalising blood cholesterol levels. A meta-analysis of 39 trials and 2,300 participants demonstrated an improvement in total cholesterol and low-density-lipoprotein (LDL) in adults with slightly elevated levels at baseline (44).

Moreover, Kyolic aged garlic extract has demonstrated to be able to normalise blood thickness. The blood thinning effect of garlic, of any type, is well known, decreasing the risk of blood clotting and thrombosis. Garlic is thought to interfere with platelet function by altering thromboxane production, preventing degranulation and interfering with the binding of fibrinogen with glycoprotein IIa/IIIa (45).

Importantly, Kyolic aged garlic extract does NOT increase the risk of bleeding, in contrast to other garlic products. A randomised double-blind placebo-controlled trial by Macan et al (2006) (46) administered warfarin (an anti-coagulant medication) to 52 patients at a dose of $10 \mathrm{~g}$ of liquid Kyolic aged garlic extract daily for 12 weeks, and assessed their increased risk of bleeding by the standard International Normalised Ratio (INR) test, finding no increased risk of bleeding in both the Kyolic garlic and the placebo group. Importantly, this trial demonstrated that Kyolic aged garlic extract differed from other garlic products, e.g., dietary garlic, and in particular raw garlic, and any warnings with regard to the increased risk of haemorrhaging are not warranted for Kyolic aged garlic extract. To the contrary, Kyolic aged garlic extract can be safely consumed before any planned surgery, and may even reduce the risk of thrombosis.

In addition to the beneficial effects of garlic on cardiovascular markers, our latest trial demonstrated a beneficial prebiotic effect on the microbiome by increasing microbial richness and microbial diversity, with the particular growth stimulation of the Lactobacillus and Clostridia species (8). Lactobacillus bacteria are generally regarded as beneficial (47), while common Clostridia species colonization in the gut has been found to activate innate immune-related genes in intestinal epithelial cells, and to prevent sensitization to food allergens in mice $(48,49)$.

In summary, this meta-analysis of 12 trials involving 553 adults with uncontrolled hypertension consolidated current evidence for garlic to be effective in reducing blood pressure 
by $8-10 \mathrm{mmHg}$ systolic and by $5-6 \mathrm{mmHg}$ diastolic, similarly to standard blood pressure medication. This decrease in blood pressure is associated with a 16-40\% risk reduction of cardiovascular events, such as heart attack and stroke. The B vitamin status is an important factor for the responsiveness of high blood pressure to garlic in each individual. Kyolic aged garlic extract in particular is highly tolerable, and can safely be consumed, in addition to other standard blood pressure medication.

Latest research has provided new evidence for Kyolic aged garlic extract to improve central haemodynamic measures, including central blood pressure and pulse pressure, and pulse wave velocity, a measure for arterial stiffness, regarded as important predictors for cardiovascular disease. Kyolic aged garlic extract has the potential to reverse the ageing of the arteries and therefore, arterial stiffness by approximately 5 years, as evidenced by a mean reduction in pulse wave velocity by $0.7 \mathrm{~m} / \mathrm{sec}$ within 3 months.

In conjunction with the normalising effects of Kyolic aged garlic extract on blood pressure, cholesterol levels and blood stickiness, Kyolic aged garlic extract provides beneficial effects on several levels important for cardiovascular health. Furthermore, prebiotic Kyolic aged garlic extract improves microbial richness and diversity in the gut, with a marked increase in the numbers of beneficial and immune-stimulating bacteria, such as Lactobacillus and Clostridia species, within a 3-month period.

Further larger and longer-term studies are warranted to assess the potential of Kyolic aged garlic extract on the gut microbiota. Moreover, it would be of interest to explore the responsiveness of high blood pressure to aged garlic extract in each individual, by investigating underlying dietary and genetic factors, such as vitamin B6 and folate levels, in addition to vitamin $\mathrm{B} 12$.

\section{Acknowledgements}

Not applicable.

\section{Funding}

This research was presented at the 2019 International Garlic Symposium in Hiroshima, Japan, supported by Wakunaga Pharmaceuticals Japan. KR received a travel sponsorship from Wakunaga Ltd. to attend the 2019 International Garlic Symposium. The sponsor was not involved in the study design, data collection, analysis and preparation of the manuscript.

\section{Availability of data and materials}

All data generated or analysed during this study are included in this published article or are available from the corresponding author on reasonable request.

\section{Authors' contributions}

KR was the chief investigator of 4 trials $(5-8)$. Trials $(5,6)$ were conducted at Adelaide University, South Australia, and trials $(7,8)$ were conducted at NIIM Melbourne, Australia. KR undertook the meta-analysis, prepared the manuscript and approved the final version for publication.

\section{Ethics approval and consent to participate}

Not applicable.

\section{Patient consent for publication}

Not applicable.

\section{Competing interests}

The author declares that this research was conducted in the absence of any commercial or financial relationships that could be construed as a potential conflict of interest.

\section{References}

1. Ried K, Frank OR, Stocks NP, Fakler P, Sullivan T. 1. Ried K, Frank OR, Stocks NP, Fakler P and Sullivan T: Effect of garlic on blood pressure: A systematic review and meta-analysis. BMC Cardiovasc Disord 8: 13, 2008.

2. Reinhart KM, Coleman CI, Teevan C, Vachhani P and White CM: Effects of garlic on blood pressure in patients with and without systolic hypertension: A meta-analysis. Ann Pharmacother 42: 1766-1771, 2008.

3. Rohner A, Ried K, Sobenin IA, Bucher HC and Nordmann AJ: A systematic review and meta-analysis on the effects of garlic preparations on blood pressure in individuals with hypertension. Am J Hypertens 28: 414-423, 2015.

4. Ried K: Effect of garlic on blood pressure, serum cholesterol and immunity: Updated meta-analyses and review. J Nutr 146: 3895-96S, 2016.

5. Ried K, Frank OR and Stocks NP: Aged garlic extract lowers blood pressure in patients with treated but uncontrolled hypertension: A randomised controlled trial. Maturitas 67: 144-150, 2010.

6. Ried K, Frank OR and Stocks NP: Aged garlic extract reduces blood pressure in hypertensives: A dose-response trial. Eur J Clin Nutr 67: 64-70, 2013.

7. Ried K, Travica N and Sali A: The effect of aged garlic extract on blood pressure and other cardiovascular risk factors in uncontrolled hypertensives: The AGE at Heart trial. Integr Blood Press Control 9: 9-21, 2016.

8. Ried K, Travica N and Sali A: The effect of kyolic aged garlic extract on gut microbiota, inflammation, and cardiovascular markers in hypertensives: The GarGIC Trial. Front Nutr 5: 122, 2018.

9. Centers for Disease Control and Prevention (CDC): Vital signs: Awareness and treatment of uncontrolled hypertension among adults - United States, 2003-2010. MMWR Morb Mortal Wkly Rep 61: 703-709, 2012

10. Olsen H, Klemetsrud T, Stokke HP, Tretli S and Westheim A: Adverse drug reactions in current antihypertensive therapy: A general practice survey of 2586 patients in Norway. Blood Pressure 8: 94-101, 1999.

11. Laurent S, Cockcroft J, Van Bortel L, Boutouyrie P, Giannattasio C, Hayoz D, Pannier B, Vlachopoulos C, Wilkinson I and StruijkerBoudier H; European Network for Non-invasive Investigation of Large Arteries: Expert consensus document on arterial stiffness: Methodological issues and clinical applications. Eur Heart J 27: 2588-2605, 2006

12. Larijani VN, Ahmadi N, Zeb I, Khan F, Flores F and Budoff M: Beneficial effects of aged garlic extract and coenzyme Q10 on vascular elasticity and endothelial function: The FAITH randomized clinical trial. Nutrition 29: 71-75, 2013.

13. Nunan D, Wassertheurer S, Lasserson D, Hametner B, Fleming S, Ward A and Heneghan C: Assessment of central haemomodynamics from a brachial cuff in a community setting. BMC Cardiovasc Disord 12: 48, 2012.

14. Nunan D, Fleming S, Hametner B and Wassertheurer S: Performance of pulse wave velocity measured using a brachial cuff in a community setting. Blood Press Monit 19: 315-319, 2014.

15. O'Rourke M: Arterial stiffness, systolic blood pressure, and logical treatment of arterial hypertension. Hypertension 15: 339-347, 1990.

16. Ried K and Fakler P: Potential of garlic (Allium sativum) in lowering high blood pressure: Mechanisms of action and clinical relevance. Integr Blood Press Control 7: 71-82, 2014. 
17. Travica N, Ried K and Sali A: Integrative Health Check reveals suboptimal levels in a number of vital biomarkers. Adv Integr Med 2: 135-140, 2015

18. Yang T, Santisteban MM, Rodriguez V, Li E, Ahmari N, Carvajal JM, Zadeh M, Gong M, Qi Y, Zubcevic J, et al: Gut dysbiosis is linked to hypertension. Hypertension 65: 1331-1340, 2015.

19. Marchesi JR, Adams DH, Fava F, Hermes GD, Hirschfield GM, Hold G, Quraishi MN, Kinross J, Smidt H, Tuohy KM, et al: The gut microbiota and host health: A new clinical frontier. Gut 65 : $330-339,2016$.

20. Sekirov I, Russell SL, Antunes LCM and Finlay BB: Gut microbiota in health and disease. Physiol Rev 90: 859-904, 2010.

21. Benavides GA, Squadrito GL, Mills RW, Patel HD, Isbell TS, Patel RP, Darley-Usmar VM, Doeller JE and Kraus DW: Hydrogen sulfide mediates the vasoactivity of garlic. Proc Natl Acad Sci USA 104: 17977-17982, 2007.

22. Filocamo A, Nueno-Palop C, Bisignano C, Mandalari G and Narbad A: Effect of garlic powder on the growth of commensal bacteria from the gastrointestinal tract. Phytomedicine 19: 707-711, 2012.

23. Motta JP, Flannigan KL, Agbor TA, Beatty JK, Blackler RW, Workentine ML, Da Silva GJ, Wang R, Buret AG and Wallace JL: Hydrogen sulfide protects from colitis and restores intestinal microbiota biofilm and mucus production. Inflamm Bowel Dis 21: 1006-1017, 2015.

24. Ng SC, Lam EF, Lam TT, Chan Y, Law W, Tse PC, Kamm MA, Sung JJ, Chan FK and Wu JC: Effect of probiotic bacteria on the intestinal microbiota in irritable bowel syndrome. J Gastroenterol Hepatol 28: 1624-1631, 2013.

25. Khalesi S, Sun J, Buys N and Jayasinghe R: Effect of probiotics on blood pressure: A systematic review and meta-analysis of randomized, controlled trials. Hypertension 64: 897-903, 2014.

26. Silagy CA and Neil HA: A meta-analysis of the effect of garlic on blood pressure. J Hypertens 12: 463-468, 1994.

27. Manager R: (RevMan) [Computer program]. Version 5.3 Copenhagen: The Nordic Cochrane Centre, The Cochrane Collaboration, 2014.

28. Kandziora J: Blutdruck und Lipidsenkende Wirkung eines Knoblauch-Präparates in Kombination mit einem Diuretikum. Blood pressure and lipid reducing effect of a garlic supplement in combination with a diuretic. Arztl Forsch 35:3-8, 1988 (In German).

29. Auer W, Eiber A, Hertkorn E, Hoehfeld E, Koehrle U, Lorenz A Mader F, Merx W, Otto G, Schmid-Otto B, et al: Hypertension and hyperlipidaemia: Garlic helps in mild cases. Br J Clin Pract Suppl 69: 3-6, 1990.

30. Vorberg G and Schneider B: Therapy with garlic: Results of a placebo-controlled, double-blind study. Br J Clin Pract Suppl 69: $7-11,1990$.

31. Holzgartner H, Schmidt U and Kuhn U: Comparison of the efficacy and tolerance of a garlic preparation vs. bezafibrate. Arzneimittelforschung 42: 1473-1477, 1992.

32. Santos O and Gruenwald J: Effect of garlic powder tablets on blood lipids and blood pressure: A six-month placebo-controlled, double-blind study. Br J Clin Res 4: 37-44, 1993.

33. Sobenin IA, Andrianova IV, Demidova ON, Gorchakova T and Orekhov AN: Lipid-lowering effects of time-released garlic powder tablets in double-blinded placebo-controlled randomized study. J Atheroscler Thromb 15: 334-338, 2008.

34. Sobenin IA, Andrianova IV, Fomchenkov IV, Gorchakova TV and Orekhov AN: Time-released garlic powder tablets lower systolic and diastolic blood pressure in men with mild and moderate arterial hypertension. Hypertens Res 32: 433-437, 2009.
35. Nakasone Y, Nakamura Y, Yamamoto $T$ and Yamaguchi $H$ : Effect of a traditional Japanese garlic preparation on blood pressure in prehypertensive and mildly hypertensive adults. Exp Ther Med 5: 399-405, 2013.

36. Mahdavi-Roshan M, Nasrollahzadeh J, Mohammad Zadeh A and Zahedmehr A: Does garlic supplementation control blood pressure in patients with severe coronary artery disease? A clinical trial study. Iran Red Crescent Med J 18: e23871, 2016.

37. Zeb F, Safdar M, Fatima S, Khan S, Alam S, Muhammad M, Syed A, Habib F and Shakoor H: Supplementation of garlic and coriander seed powder: Impact on body mass index, lipid profile and blood pressure of hyperlipidemic patients. Pak J Pharm Sci 31: 1935-1941, 2018.

38. Kyolic Aged Garlic Extract Reserve formula. Wakunaga of America Co. Ltd., Mission Viejo, CA, USA. Available from: http://www.kyolic.com/product/category/reserve/.

39. Amagase $\mathrm{H}$ : Clarifying the real bioactive constituents of garlic. J Nutr 136 (Suppl): 716S-725S, 2006.

40. Amagase H, Petesch BL, Matsuura H, Kasuga S and Itakura Y: Intake of garlic and its bioactive components. J Nutr 131: 955S-962S, 2001.

41. Lewington S, Clarke R, Qizilbash N, Peto R and Collins R; Prospective Studies Collaboration: Age-specific relevance of usual blood pressure to vascular mortality: A meta-analysis of individual data for one million adults in 61 prospective studies. Lancet 360: 1903-1913, 2002.

42. Ettehad D, Emdin CA, Kiran A, Anderson SG, Callender T, Emberson J, Chalmers J, Rodgers A and Rahimi K: Blood pressure lowering for prevention of cardiovascular disease and death: A systematic review and meta-analysis. Lancet 387: 957-967, 2016.

43. Beard RS Jr and Bearden SE: Vascular complications of cystathionine $\beta$-synthase deficiency: Future directions for homocysteine-to-hydrogen sulfide research. Am J Physiol Heart Circ Physiol 300: H13-H26, 2011.

44. Ried K, Toben C and Fakler P: Effect of garlic on serum lipids: An updated meta-analysis. Nutr Rev 71: 282-299, 2013.

45. Rahman K: Effects of garlic on platelet biochemistry and physiology. Mol Nutr Food Res 51: 1335-1344, 2007.

46. Macan H, Uykimpang R, Alconcel M, Takasu J, Razon R, Amagase $\mathrm{H}$ and Niihara $\mathrm{Y}$ : Aged garlic extract may be safe for patients on warfarin therapy. J Nutr 136 (Suppl 3): 793S-795S, 2006.

47. Slavin J: Fiber and prebiotics: Mechanisms and health benefits. Nutrients 5: 1417-1435, 2013.

48. Stefka AT, Feehley T, Tripathi P, Qiu J, McCoy K, Mazmanian SK, Tjota MY, Seo G-Y, Cao S, Theriault BR, et al: Commensal bacteria protect against food allergen sensitization. Proc Natl Acad Sci USA 111: 13145-13150, 2014.

49. Feehley T, Stefka AT, Cao S and Nagler CR: Microbial regulation of allergic responses to food. Semin Immunopathol 34: 671-688, 2012.

This work is licensed under a Creative Commons Attribution-NonCommercial-NoDerivatives 4.0 International (CC BY-NC-ND 4.0) License. 